1 Fundação Oswaldo Cruz (Fiocruz), Instituto Nacional de Controle de Qualidade em Saúde (INCQS) - Rio de Janeiro (RJ), Brasil.

cristovao.s.alves@hotmail. com

2 Fundação Oswaldo Cruz (Fiocruz), Instituto Nacional de Controle de Qualidade em Saúde (INCQS) - Rio de Janeiro (RJ), Brasil. michele.feitoza@incas. fiocruz.br

3 Fundação Oswaldo Cruz (Fiocruz), Instituto Nacional de Controle de Qualidade em Saúde (INCQS) - Rio de Janeiro (RJ), Brasil.

katia.leandro@incas.fiocruz. br

4 Universidade Federal do Rio de Janeiro (UFRJ), Instituto de Química - Rio de Janeiro (RJ), Brasil. andre.gemal@gmail.com

\section{Perfil de queixas técnicas relacionadas a seringas hipodérmicas de uso único comercializadas no Brasil após certificação compulsória}

\author{
Profile of technical complaints related to single use hypodermic \\ syringes marketed in Brazil after compulsory certification
}

Cristovão de Sousa Alves², Michele Feitoza Silva², Kátia Christina Leandro ${ }^{\mathbf{3}}$, André Luís Gemal4

RESUMO A certificação metrológica é uma importante ferramenta de Vigilância Sanitária. O objetivo deste estudo foi avaliar o perfil das notificações de queixas técnicas de seringas hipodérmicas realizadas no Notivisa/Anvisa (Sistema Nacional de Notificações de Eventos Adversos e Queixas Técnicas/Agência Nacional de Vigilância Sanitária) entre 2012 e 2015. As notificações foram analisadas individualmente e classificadas conforme os motivos relatados. Foram avaliadas 4181 notificações, e as queixas mais prevalentes foram: 'produto quebrado na embalagem lacrada' (22\%) e 'sujidade/manchas no interior do produto/embalagem' $(15,8 \%)$. Não foram observadas alterações significativas no perfil das queixas após a certificação compulsória, que, embora imprescindível, não é capaz de substituir o monitoramento pós-comercialização.

PALAVRAS-CHAVE Certificação. Regulação e fiscalização em saúde. Seringas. Sistema de informação. Vigilância de produtos comercializados.

\begin{abstract}
Metrological certification is an important Sanitary Surveillance tool. The objective of this study was to evaluate the profile of notifications of technical complaints of hypodermic syringes performed in Notivisa/Anvisa (Sistema Nacional de Notificações de Eventos Adversos e Queixas Técnicas/Agência Nacional de Vigilância Sanitária) between 2012 and 2015. The notifications were analyzed individually and classified according to the reasons reported. 4181 notifications were evaluated and the most prevalent complaints were: 'broken product in the sealed package' (22\%) and 'dirt/stains inside the product/packaging' (15.8\%). There were no significant changes in the profile of the complaints after compulsory certification, which, although indispensable, is not capable of replacing post-marketing monitoring.
\end{abstract}

KEYWORDS Certification. Health care coordination and monitoring. Syringes. Information systems. Product surveillance postmarketing. 


\section{Introdução}

As seringas hipodérmicas de uso único são produtos para saúde, também denominados produtos médicos, utilizados para a administração de preparações injetáveis, em procedimentos que envolvem prevenção, diagnóstico e anticoncepção. São fornecidas estéreis e isentas de pirogênios e não devem ser reesterilizadas ou reutilizadas ${ }^{\mathbf{1}-3}$.

De um modo geral, esse produto é composto por um corpo cilíndrico transparente em polipropileno grau médico, graduado, tendo um bico cônico ou rosqueado em uma extremidade, que permita o acoplamento a uma agulha ou outros dispositivos, e, na outra extremidade, um conjunto pistão/ haste (êmbolo) de borracha atóxica, que desliza pelo interior do corpo cilíndrico. Os materiais usados na fabricação de seringas não estão especificados, pois sua seleção depende do projeto, do processo de produção e do método de esterilização empregados por cada fabricante. Cada seringa é apresentada com proteção individual para manter a esterilidade ${ }^{4-6}$.

Sendo assim, as seringas devem atender a requisitos mínimos de identidade e qualidade, tais como: não conter partículas e materiais estranhos por meio de verificação visual normal; não conter gotas de lubrificante nas superfícies interna e externa da seringa por meio de inspeção visual normal; não exceder $0,25 \mathrm{mg} / \mathrm{cm}^{2}$ de lubrificante (exceto as seringas para insulina); possuir desenho da haste e da base da haste da seringa que assegure que o pistão não se desconecte; não haver vazamento de ar ou líquido através do pistão $0^{\mathbf{4} 5}$.

Devido à sua ampla utilização, desvios da qualidade desse produto podem ocasionar agravos em um elevado número de pessoas, causando grande impacto na saúde pública ${ }^{2,7}$.

O Sistema Nacional de Vigilância Sanitária (SNVS) tem como principal atribuição a promoção e a proteção da saúde, além de promover o desenvolvimento de mecanismos de vigilância pós-comercialização que permitam reunir informações sobre o desempenho e a segurança do produto em sua fase de utilização. Por conseguinte, o SNVS conta com a colaboração dos hospitais da Rede Sentinela e dos demais serviços de saúde, dos serviços de apoio a diagnóstico e terapêutica, dos profissionais de saúde, dos usuários e, também, dos próprios órgãos de Vigilância Sanitária (Visa) ${ }^{2,7-9}$.

O Sistema Nacional de Notificações de Eventos Adversos e Queixas Técnicas (Notivisa) é o sistema informatizado desenvolvido para receber notificações de Eventos Adversos (EA) e Queixas Técnicas (QT) geradas pelos hospitais da Rede Sentinela, por empresas detentoras de registro, profissionais de saúde e, também, por cidadãos. As informações geradas por esse sistema auxiliam nas ações de regulação sanitária visando à minimização de riscos e problemas relacionados ao produto, que, muitas vezes, só são identificados no período de comercialização do produto ${ }^{2,9-11}$. Ainda que as subnotificações e as não notificações fragilizem a robustez da informação, o Notivisa é um sistema extremamente útil na sinalização de ações em Visa.

Com o elevado número de notificações relacionadas a falhas e problemas da qualidade, e visando garantir as condições adequadas de segurança no momento da utilização de produtos, a Agência Nacional de Vigilância Sanitária (Anvisa) foi impulsionada à publicação, em 2011, de regulamentos específicos que tornaram compulsória a certificação metrológica de alguns produtos. Entre elas estava a Resolução RDC n ${ }^{\circ} 3$, de 4 de fevereiro de 2011, que estabeleceu requisitos mínimos de identificação e qualidade para seringas hipodérmicas ${ }^{5}$. E, com direcionamento para a regulamentação, o Instituto Nacional de Metrologia, Qualidade e Tecnologia (Inmetro) publicou, em 29 de dezembro de 2011, a Portaria ${ }^{\circ} 503$, que determinou a certificação metrológica compulsória ${ }^{12}$ deste produto, com base na avaliação

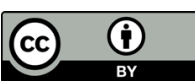

Este é um artigo publicado em acesso aberto (Open Access) sob a licença Creative Commons Attribution, que permite uso, distribuição e reprodução em qualquer meio, sem restrições, desde que o trabalho original seja corretamente citado. 
da qualidade das seringas com relação aos parâmetros preconizados pela Norma ABNT (Associação Brasileira de Normas Técnicas) NBR ISO no 7886-1:20034.

A RDC no 3/2011 determinou o prazo de 360 dias para adequação dos detentores de registro e a consequente obrigatoriedade da certificação dos seus produtos por organismos acreditados pelo Inmetro a partir de 2012, porém, esse prazo foi postergado para 30 de junho de 20135.

O presente trabalho é um estudo descritivo exploratório relativo ao período de 2012 a 2015, apresentado em série histórica que objetivou analisar o perfil das notificações de queixas técnicas relacionadas ao produto seringa, registradas no Notivisa, durante processo de certificação compulsória.

\section{Metodologia}

Todas as notificações relacionadas às seringas hipodérmicas de uso único registradas no Notivisa, no período de 2012 a 2015, foram solicitadas ao Núcleo de Gestão do Sistema Nacional de Notificação e Investigação em Vigilância Sanitária (Nuvig/Anvisa).

Após o recebimento, por meio digital, os registros de notificações foram tratados em editor de planilhas, classificados e avaliados utilizando os seguintes filtros: período, nome do produto (seringa) e tipo de evento (queixa técnica). Para efeito deste estudo, foi escolhido o período de 2012 a 2015, pois a certificação compulsória para o produto em questão passou a valer a partir de 2013.

O número total de queixas técnicas registradas no Notivisa foi quantificado e analisado por ano no período proposto. As queixas técnicas originais foram analisadas individualmente e classificadas em 5 grupos (funcionalidade, embalagem, aspecto, registro e outros); e, posteriormente, visando uniformizar e organizar a diversidade de formas de notificação de um mesmo problema, as queixas técnicas originais foram reclassificadas individualmente em subgrupos, construídos com base nos critérios de conformidade estabelecidos pela Resolução $\mathrm{RDC} \mathrm{n}^{\circ} 3$, de 4 de fevereiro de $2011^{5}$. A partir da identificação e da quantificação dos problemas apontados, estabeleceu-se, assim, o perfil das notificações de queixas técnicas no período e os motivos de maior prevalência por ano.

Os detentores de registro, cujos produtos receberam notificações no sistema Notivisa, foram identificados, e as respectivas notificações foram quantificadas dentro do período em estudo. Dessa forma, foi possível avaliar os principais detentores tendo em vista o total de notificações do período e o número de notificações por ano. Para preservar a identidade de cada empresa, foram atribuídos a elas, em ordem alfabética, uma codificação alfanumérica constituída da letra ' $\mathrm{D}$ ', seguida de um número sequencial de identificação.

Os resultados encontrados foram organizados em tabelas e gráficos para melhor apresentação e análise dos resultados.

\section{Resultados e discussão}

Entre 2012 e 2015 , foram registradas, respectivamente, 1126 (2012), 1023 (2013), 950 (2014) e 1082 (2015) notificações, totalizando 4181 notificações de queixas técnicas associadas a seringas hipodérmicas registradas no sistema Notivisa. A notificação é voluntária para profissionais de saúde e a população em geral, e obrigatória para os detentores de registro e os serviços de saúde, sendo assim, a possibilidade de subnotificação não deve ser descartada ${ }^{\mathbf{1 3}, \mathbf{1 4}}$. Existe, também, a possibilidade de que algumas ocorrências tenham sido investigadas e concluídas por órgãos de Visa estaduais ou municipais e não tenham sido incluídas no sistema Notivisa.

A tabela 1 apresenta os diferentes tipos de notificações de queixas técnicas sobre seringas hipodérmicas de uso único 
registradas no Notivisa durante o período estudado. A partir da classificação realizada pelos autores, segundo as normas vigentes, foram verificadas não conformidades relacionadas à funcionalidade (32,7\%); à embalagem (37,6\%); a aspecto (27,8\%); somente 1 (uma) notificação para registro do produto junto à Anvisa; e outros (1,7\%). Essa classificação foi de grande relevância devido à heterogeneidade das notificações e à pluralidade dos agentes notificantes.

Tabela 1. Registros de queixas técnicas relacionadas às seringas hipodérmicas de uso único no período de 2012 a 2015

\begin{tabular}{|c|c|c|c|c|c|c|}
\hline \multirow{2}{*}{ Descrição das Queixas Técnicas } & \multicolumn{6}{|c|}{ Número de notificações } \\
\hline & 2012 & 2013 & 2014 & 2015 & Total & $\%$ \\
\hline \multicolumn{7}{|l|}{ Funcionalidade } \\
\hline Vazamento de líquido ou ar pelo cilindro da seringa & 131 & 123 & 63 & 68 & 385 & 8,6 \\
\hline Êmbolo se desprende, com facilidade, do cilindro da seringa & 61 & 88 & 101 & 73 & 323 & 7,2 \\
\hline Baixa resistividade ao manuseio & 55 & 99 & 40 & 81 & 275 & 6,1 \\
\hline Problemas de encaixe ou conexão com agulha ou outros dispositivos & 49 & 71 & 70 & 71 & 261 & 5,8 \\
\hline Seringa não aspira & 6 & 13 & 46 & 7 & 72 & 1,6 \\
\hline Problemas com o dispositivo de segurança & 25 & 25 & 16 & 11 & 77 & 1,7 \\
\hline Êmbolo não desliza ou desliza com dificuldade & 16 & 10 & 16 & 35 & 77 & 1,7 \\
\hline \multicolumn{7}{|l|}{ Embalagem } \\
\hline $\begin{array}{l}\text { Embalagem defeituosa, prejudicando a abertura ou comprometendo a } \\
\text { esterilidade }\end{array}$ & 41 & 45 & 25 & 55 & 166 & 3,7 \\
\hline $\begin{array}{l}\text { Ausência do produto ou de partes dentro da embalagem lacrada ou ime- } \\
\text { diatamente aberta }\end{array}$ & 118 & 94 & 134 & 138 & 484 & 10,8 \\
\hline Problemas na Rotulagem que dificultam a identificação do lote e da validade & 3 & 19 & 10 & 16 & 48 & 1,1 \\
\hline Produto ou parte quebrada, na embalagem lacrada ou logo após a abertura & 299 & 234 & 217 & 237 & 987 & 22,0 \\
\hline \multicolumn{7}{|l|}{ Aspecto } \\
\hline $\begin{array}{l}\text { Presença de sujidade, mancha ou corpo estranho no interior do produto } \\
\text { ou no interior da embalagem }\end{array}$ & 202 & 169 & 172 & 166 & 709 & 15,8 \\
\hline Problemas na graduação da seringa & 64 & 49 & 64 & 137 & 314 & 7,0 \\
\hline Presença de excesso de lubrificante no interior da seringa & 27 & 11 & 12 & 176 & 226 & 5,0 \\
\hline \multicolumn{7}{|l|}{ Registro } \\
\hline Registro vencido na Anvisa & 0 & 0 & 0 & 1 & 1 & 0,0 \\
\hline Outros & 27 & 22 & 10 & 18 & 77 & 1,7 \\
\hline Total & 1124 & 1072 & 996 & 1290 & $4482^{\star}$ & 100 \\
\hline
\end{tabular}

*Por vezes, houve mais de um tipo de não conformidade na mesma notificação, assim, o número total de queixas técnicas (4482) foi maior que o total de notificações realizadas no Notivisa (4181).

Posteriormente à classificação nos 5 grupos, as notificações foram reclassificadas em 15 subgrupos, construídos com base nos artigos presentes no regulamento técnico publicado pela Anvisa5, o que possibilitou, a partir dos critérios de qualidade estabelecidos para seringas hipodérmicas de uso único, a avaliação com maior detalhamento dos problemas observados/relatados pelos notificadores.

Entre as queixas técnicas reclassificadas, o 'produto ou parte dele quebrado, na 
embalagem lacrada ou imediatamente após sua abertura' (22,0\%), a 'presença de sujidade, mancha ou corpo estranho no interior do produto ou da embalagem' (15,8\%) e a 'ausência do produto ou parte dele dentro da embalagem lacrada ou imediatamente após abertura' $(10,8 \%)$ foram algumas das causas de maior prevalência observadas. Essas não conformidades podem estar associadas a problemas no controle do processo de fabricação e dos ambientes fabris, assim como aos procedimentos de armazenamento e empilhamento das seringas ${ }^{15-17}$.

Outros problemas com grande expressão em número de notificações foram: o 'vazamento de líquido ou ar pelo cilindro da seringa' (8,6\%) e 'o êmbolo se desprende, com facilidade, do cilindro da seringa' (7,2\%). Tanto o vazamento quanto o desprendimento do êmbolo são problemas graves de funcionalidade que podem estar relacionados a erros no processo de fabricação e denotam um risco potencial, principalmente ao profissional de saúde que manipula medicamentos ou produtos químicos. Em diversas situações, a ocorrência desses problemas pode causar lesões, como é o caso de alguns quimioterápicos vesicantes, além de ocasionar prejuízos com a perda de produto, muitas das vezes com alto valor comercial e que também exigem um controle rigoroso nas doses a serem administradas ${ }^{18-22}$. Com relação à ocorrência de vazamentos, observa-se, também, uma redução considerável, em torno de $50 \%$, do número de notificações em relação aos anos de 2013 (123 notificações) e 2014 (63 notificações), tendência que se manteve em 2015 (68 notificações). Essa redução pode estar relacionada a uma possível adequação das empresas na solução desses problemas após a certificação compulsória.

Duas outras situações que chamaram a atenção foram o expressivo aumento do número de casos de 'problemas na graduação da seringa' e 'presença de excesso de lubrificante no interior da seringa', entre os anos de 2014 e 2015, onde se observaram aumentos de mais de $200 \%$ e $1.000 \%$, respectivamente. Esse expressivo aumento acende o alerta quanto aos mecanismos hoje utilizados na regulação e no controle da qualidade das seringas. Com relação a esses itens, vale a pena refletir sobre os processos de certificação compulsória, fiscalização (por parte dos órgãos competentes) e a efetividade dos parâmetros de aceitação estipulados na legislação vigente.

Apenas uma notificação, no ano de 2015, foi relacionada a um produto em uso cujo registro junto à Anvisa encontrava-se vencido. As notificações cujas não conformidades não se enquadraram nas classificações estipuladas, ou que não possuíam uma descrição clara do problema apresentado, foram classificadas como outros (1,7\%), entre elas, grande parte estava relacionada a problemas com as agulhas: 'não fura', 'torta', 'obstruída', 'com jato duplo'.

Podemos observar uma proximidade entre os números totais de notificações nos anos avaliados, o que demonstra que, pelos dados contidos no Notivisa, não é possível, ainda, observar diferenças significativas após a implementação da certificação metrológica (2013), já que, em 2014, 996 notificações foram realizadas, o que representa um decréscimo de cerca de 7\%, que em 2015 não se sustentou (aumento de $20 \%$ no número de notificações).

Na figura 1, estão apresentados os quatro motivos de maior prevalência no período estudado, por ano. Ao observar a tabela, é possível constatar que 'produto ou parte quebrada, na embalagem lacrada ou logo após a abertura' foi o motivo mais prevalente em todos os anos do estudo proposto. No ano da compulsoriedade da certificação metrológica para seringas hipodérmicas (2013), observou-se, ainda, um decréscimo (cerca de 20\%) no número de notificações para esse motivo, o que, possivelmente, demonstra uma atenção por parte dos fabricantes. 
Figura 1. Motivos de maior prevalência de notificações de queixas técnicas, relacionados a seringas hipodérmicas, por ano

\begin{tabular}{|c|c|c|}
\hline \multicolumn{3}{|c|}{2012} \\
\hline Classificação & Motivo & $\begin{array}{c}\text { Total de } \\
\text { Notificações }\end{array}$ \\
\hline 10 & $\begin{array}{l}\text { Produto ou parte quebrada, na embala- } \\
\text { gem lacrada ou logo após a abertura }\end{array}$ & 299 \\
\hline $2 \circ$ & $\begin{array}{c}\text { Presença de sujidade, mancha ou corpo } \\
\text { estranho no interior do produto ou no } \\
\text { interior da embalagem }\end{array}$ & 202 \\
\hline $3 ㅇ$ & $\begin{array}{l}\text { Vazamento de líquido ou ar pelo cilindro } \\
\text { da seringa }\end{array}$ & 131 \\
\hline $4^{\circ}$ & $\begin{array}{l}\text { Ausência do produto ou de partes den- } \\
\text { tro da embalagem lacrada ou imediata- } \\
\text { mente aberta }\end{array}$ & 118 \\
\hline
\end{tabular}

\begin{tabular}{|c|c|c|}
\hline \multicolumn{3}{|c|}{2013} \\
\hline Classificação & Motivo & $\begin{array}{c}\text { Total de } \\
\text { Notificações }\end{array}$ \\
\hline $1 \stackrel{0}{1}$ & $\begin{array}{l}\text { Produto ou parte quebrada, na embala- } \\
\text { gem lacrada ou logo após a abertura }\end{array}$ & 234 \\
\hline $2^{\circ}$ & $\begin{array}{l}\text { Presença de sujidade, mancha ou corpo } \\
\text { estranho no interior do produto ou no } \\
\text { interior da embalagem }\end{array}$ & 169 \\
\hline 3 & $\begin{array}{l}\text { Vazamento de líquido ou ar pelo cilindro } \\
\text { da seringa }\end{array}$ & 123 \\
\hline $4^{\circ}=$ & Baixa resistividade ao manuseio & 99 \\
\hline
\end{tabular}

\begin{tabular}{|c|c|c|}
\hline \multicolumn{3}{|c|}{2014} \\
\hline Classificação & Motivo & $\begin{array}{c}\text { Total de } \\
\text { Notificações }\end{array}$ \\
\hline 10 & $\begin{array}{l}\text { Produto ou parte quebrada, na embala- } \\
\text { gem lacrada ou logo após a abertura }\end{array}$ & 217 \\
\hline $2^{\circ}=$ & $\begin{array}{c}\text { Presença de sujidade, mancha ou corpo } \\
\text { estranho no interior do produto ou no } \\
\text { interior da embalagem }\end{array}$ & 172 \\
\hline 30 & $\begin{array}{l}\text { Ausência do produto ou de partes den- } \\
\text { tro da embalagem lacrada ou imediata- } \\
\text { mente aberta }\end{array}$ & 134 \\
\hline $4 ㅇ$ & Baixa resistividade ao manuseio & 5 \\
\hline
\end{tabular}

\begin{tabular}{|c|c|c|}
\hline \multicolumn{3}{|c|}{2015} \\
\hline Classificação & Motivo & $\begin{array}{c}\text { Total de } \\
\text { Notificações }\end{array}$ \\
\hline 10 & $\begin{array}{l}\text { Produto ou parte quebrada, na embala- } \\
\text { gem lacrada ou logo após a abertura }\end{array}$ & 237 \\
\hline $2^{\circ}$ & $\begin{array}{c}\text { Presença de sujidade, mancha ou corpo } \\
\text { estranho no interior do produto ou no } \\
\text { interior da embalagem }\end{array}$ & 176 \\
\hline 30 & $\begin{array}{l}\text { Vazamento de líquido ou ar pelo cilindro } \\
\qquad \text { da seringa }\end{array}$ & 166 \\
\hline 40 & Baixa resistividade ao manuseio & 138 \\
\hline
\end{tabular}

Também foi observado decréscimo relacionado ao segundo motivo mais prevalente em três dos quatro anos estudados ('Presença de sujidade, mancha ou corpo estranho no interior do produto ou no interior da embalagem'), de cerca de $16 \%$ e $15 \%$ para 2013 e 2014 , respectivamente. No ano de 2015 , esse motivo não aparece como segundo maior, mas também não foi observado decréscimo significativo de 2014 para 2015 (172 e 166 notificações, respectivamente).

Outra observação relevante está vinculada ao grande número de notificações relacionadas à 'presença de excesso de lubrificante no interior da seringa' no ano de 2015, que ocorreu devido a um programa de monitoramento realizado pelo Instituto Nacional de Controle de Qualidade em Saúde (INCQS), em parceria com o Ministério da Saúde, onde 174 amostras foram analisadas.

Com base nas análises das QTs, verificou-se, ainda, que 49 empresas detentoras de registro tiveram seus produtos apontados com suspeita de defeitos/falhas. Dessas, 36 empresas apresentaram quantitativo de QTs, em relação ao valor absoluto de notificações no período de 2012 a 2015, inferior a $1 \%$, e, para facilitar a representação em gráfico dos resultados, as notificações foram reunidas e reclassificadas como 'outros', representando, assim, $4 \%$ do total no período (4181), conforme gráfico 1 . 
Gráfico 1. Percentual de notificações de queixas técnicas por detentor de registro de seringas hipodérmicas de uso único registradas no Notivisa no período de 2012 a 2015

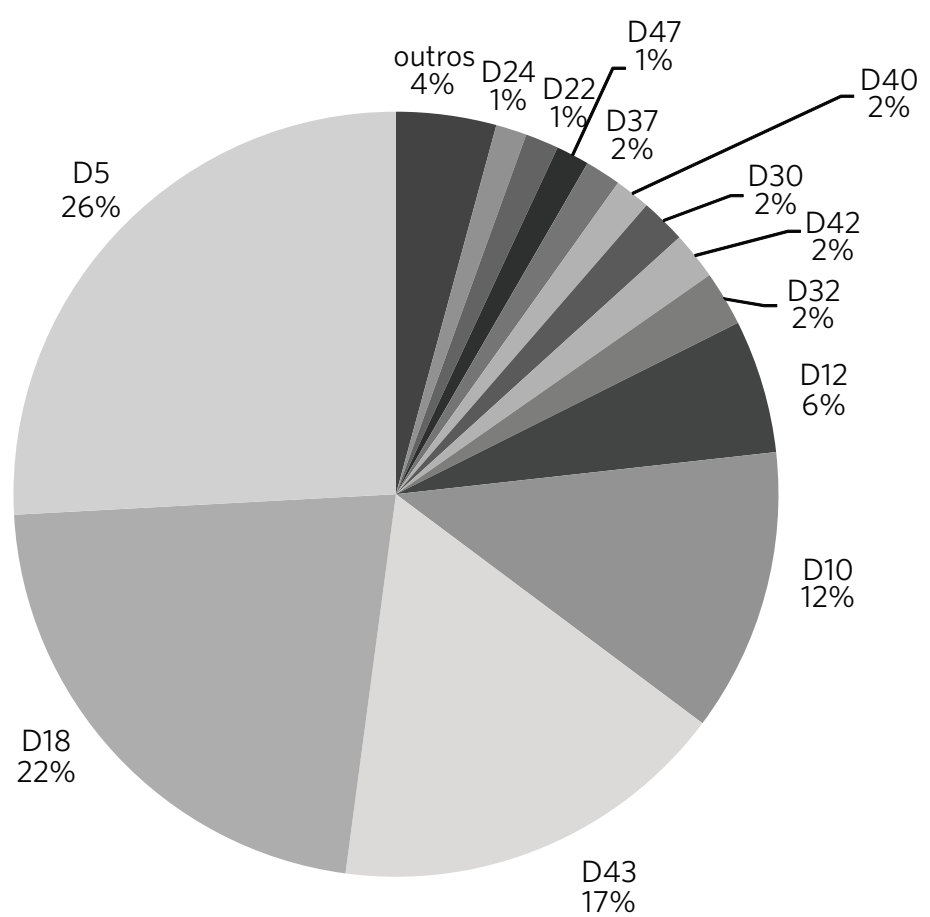

Conforme observado no gráfico 1 , as cinco empresas com maior número de notificações, D5 (1074), D18 (917), D43 (701), D10 (497) e D12 (234), no período estudado, respectivamente, representaram mais de $80 \%$ do total de QTs. Entre elas, as empresas D5 (26\%) e D18 (22\%), juntas, representaram percentual próximo a $50 \%$ do total de notificações. Mas não podemos atribuir esse elevado percentual somente a questões relativas à qualidade do produto, pois quanto maior a quantidade comercializada, maior é a probabilidade de problemas e notificações relativas ao produto, assim como maiores são os riscos de danos aos usuários.

No gráfico 2, foram apresentados os quantitativos de QTs por ano das cinco empresas com maior índice de notificações quanto à suspeita de defeitos/falhas. 
Gráfico 2. Número de notificações de queixas técnicas por detentor de registro por ano, registradas no Notivisa, no período de 2012 a 2015

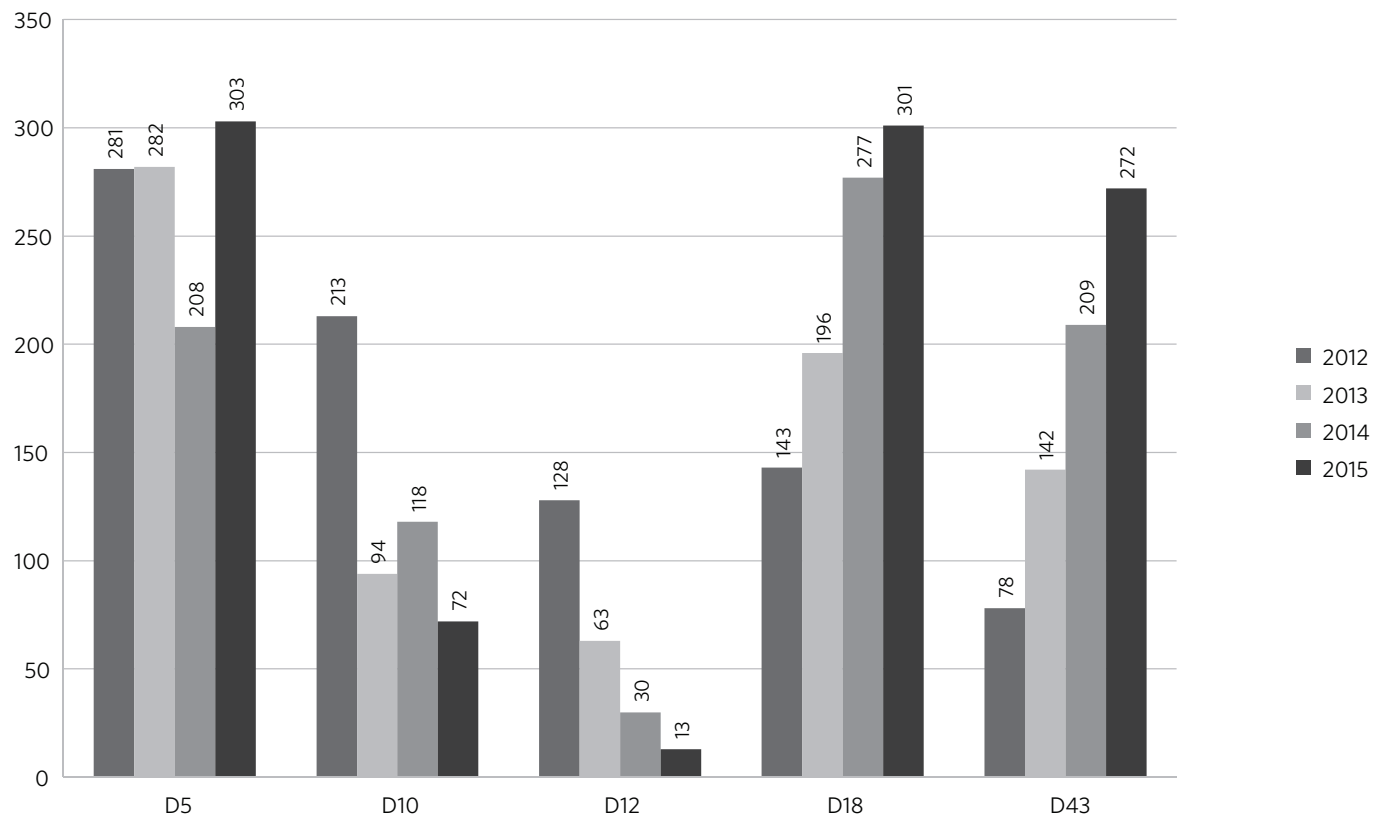

Para a empresa com maior número de notificações, D5, o quantitativo de queixas manteve-se estável nos anos de 2012 e 2013, período compreendido como de adequação às normas de qualidade estabelecidas para os produtos, com uma queda em torno de $25 \%$, em 2014, em relação ao ano anterior, e, em 2015, um aumento de cerca de $45 \%$ nas queixas em relação a 2014. Para a segunda empresa com maior número de notificações, D18, o perfil apresentado foi diferente do da empresa D5, onde se observa um aumento a cada ano, chegando a mais que dobrar o número de notificações entre 2012 e 2015 . O mesmo perfil de D18 pode ser observado em D43, terceira empresa com maior número de notificações, porém, o aumento do número de notificações com relação a 2012 e 2015 foi superior ao triplo. Já as empresas D10 e D12, respectivamente, quinta e quarta empresas com maior numero de notificações, apresentaram um perfil decrescente no número de notificações por ano, de cerca de $66 \%$ e $90 \%$, respectivamente, podendo indicar que a certificação metrológica possivelmente impactou os processos da qualidade.

A partir desses dados, podemos inferir que as empresas detentoras de registro não estão cumprindo os critérios de qualidade estabelecidos $^{5}$, tampouco desenvolvendo um adequado gerenciamento de risco dos seus produtos. É importante ressaltar que as seringas hipodérmicas são produtos para saúde de enorme utilização e que, embora seu risco, determinado pela $\mathrm{RDC} \mathrm{n}^{\circ} 185$, de 22 de outubro de 2001, seja baixo, desvios na sua qualidade podem acometer um elevado número de pessoas, e, além disso, a existência de falhas no produto pode ter como impacto um aumento de gastos com insumos hospitalares'. Cabe ao SNVS o monitoramento, a análise e a investigação desses desvios de qualidade, ainda que existam limitações quanto aos recursos humanos, para atuação exclusiva em analises pós-comercialização, e de laboratórios estruturados e acreditados para análises desses produtos ${ }^{7,9}$.

É importante ressaltar que a 
responsabilidade quanto à garantia da qualidade do produto é da empresa detentora do registro, cabendo a ela as medidas de correção e prevenção de recorrência de falhas identificadas, assim como, se necessário, a alteração de seus projetos, de modo a garantir a segurança dos usuários ${ }^{23}$.

Os dados apresentados mostram, também, a importância da participação social, neste contexto, representada pelos profissionais de saúde, serviços de saúde e usuários, por intermédio das notificações que auxiliam no acompanhamento da qualidade dos produtos pós-comercialização, assim como do sistema de notificação, o Notivisa, que permite essa integração entre os Órgãos de Visa e a sociedade, servindo como uma importante ferramenta no auxilio das tomadas de medidas tanto por parte do SNVS quanto da própria empresa ${ }^{7,24}$.

Como uma medida preventiva de segurança, nos casos de queixas técnicas relacionadas a um produto, o estabelecimento de saúde deveria segregar todas as unidades do mesmo lote. Contudo, essa medida pode levar ao desabastecimento do produto, sobretudo em unidades públicas de saúde, onde a aquisição é feita por meio de processo licitatório, que é realizado em diversas etapas e que, por vezes, não permite uma rápida aquisição/reposição.

Sendo assim, os estabelecimentos, por parte dos serviços de saúde, tanto públicos quanto privados, de critérios de pré-qualificação de seus fornecedores, nos editais de aquisição de produtos, a fim de favorecer a qualidade, sem detrimento do custo, poderão colaborar para a aquisição de produtos seguros e eficazes.

\section{Conclusões}

No período do estudo, foram notificadas 4181 queixas técnicas para o produto seringa hipodérmica de uso único, sendo que o ano de maior número de notificações foi 2015 , talvez devido a um programa realizado em parceria entre o Ministério da Saúde e o INCQS, que não ocorreu nos anos anteriores (174 amostras).

As queixas técnicas de maior prevalência foram relacionadas a: quebra do produto (22\%), presença de sujidade/manchas $(15,8 \%)$ e ausência de partes na embalagem primária $(10,8 \%)$. Vale chamar a atenção para o motivo 'presença de excesso de lubrificante', que foi o $2^{\circ}$ maior motivo de notificações somente no ano de 2015.

A classificação proposta em cinco grupos (funcionalidade, embalagem, aspecto, registro e outros) facilitou a avaliação individual das notificações, que, devido ao grande número de problemas relacionados ao produto e, ainda, pela grande diversidade de notificações, são apresentadas de forma não organizada.

Não foi possível identificar diferenças significativas no número de notificações realizadas no Notivisa, após a implementação da certificação metrológica (2013), para seringas hipodérmicas de uso único.

A certificação metrológica vem sendo apontada como uma ferramenta para o SNVS, no entanto, não pode substituir o monitoramento do mercado. O Notivisa é, também, uma ferramenta e, assim como tantas outras, não pode ser utilizada sozinha.

Por fim, evidenciam-se estudos relacionados a queixas técnicas e eventos adversos de produtos de âmbito sanitário à necessidade da construção de programas de monitoramento que possibilitem reforçar ações de vigilância pós-comercialização. Ações que devem ser compreendidas como responsabilidade de todos os entes do SNVS.

A análise de dados oriundos do sistema Notivisa, apesar das fragilidades das subnotificações (notificações incompletas e sem ajustes de classificação), pode, sim, ser uma norteadora para as ações de Visa.

No que se refere ao impacto das certificações compulsórias (não só para as seringas hipodérmicas, mas, também, para outros materiais médicos certificados no Brasil), a 
avaliação dos dados notificados nos proporciona duas importantes reflexões: o que se esperava com o processo de certificação metrológica e quais passos estão sendo construídos para o monitoramento racional desses produtos?

$\mathrm{O}$ que realmente independe das respostas desses dois pontos apresentados é que trata-se de dois processos/caminhos diferentes, paralelos, e que principalmente o monitoramento no local de uso não pode ser substituído.

\section{Colaboradores}

Cristovão de Sousa Alves - contribuiu substancialmente para a concepção, o planejamento, a análise, a interpretação dos dados e a elaboração do rascunho.

Michele Feitoza Silva - contribuiu substancialmente para a concepção, o planejamento, a análise, a interpretação dos dados, a elaboração do rascunho e a aprovação final do manuscrito.

Kátia Christina Leandro - contribuiu substancialmente para a concepção, o planejamento, a análise e a interpretação dos dados.

André Luís Gemal - contribuiu substancialmente para a revisão crítica do conteúdo e a aprovação da versão final do manuscrito.

\section{Referências}

1. Agência Nacional de Vigilância Sanitária (Brasil). Resolução RDC $n^{\circ}$ 185, de 22 de outubro de 2001. Dispõe sobre regulamento técnico para registro, alteração, revalidação e cancelamento do registro de produtos médicos na Agência Nacional de Vigilância Sanitária. Diário Oficial da União. 6 Nov 2001.

2. Feitoza-Silva M, Fernandes BS, Carvalho SFR, et al. Certificação compulsória e qualidade de agulhas e seringas em um Hospital Sentinela. Vigil Sanit Debate. 2016; 4(2):21-26.

3. Ministério do Desenvolvimento, Indústria e Comércio Exterior. Instituto Nacional de Metrologia, Normalização e Qualidade Industrial. Programa de análise de produtos: relatório sobre análise em seringas e agulhas hipodérmicas estéreis de uso único. [Rio de Janeiro]: Inmetro; 2010 [acesso em 2017 abr 4]. Disponível em: http://www.inmetro.gov.br/consumidor/produtos/seringas_agulhas.pdf.

4. Associação Brasileira de Normas Técnicas. NBR
ISO 7886-1:2003: Seringa hipodérmica estéril para uso único. Parte 1: Seringa para uso manual. Rio de Janeiro: ABNT; 2011.

5. Agência Nacional de Vigilância Sanitária (Brasil). Resolução RDC $n^{\circ}$ 3, de 4 de fevereiro de 2011. Estabelece os requisitos mínimos de identidade e qualidade para as seringas hipodérmicas e agulhas gengivais. Diário Oficial da União. 7 Fev 2011.

6. British Pharmacopeia. London: Her Majesty's Stationery Office; 2016.

7. Branco NMC, Lopes RGA, Silva MF, et al. NOTIVISA e os Laboratórios de Saúde Pública: A interface da informação em Vigilância Sanitária. Vigil Sanit Debate. 2015; 3(3):130-134.

8. Agência Nacional de Vigilância Sanitária. Cartilha de notificações em tecnovigilância. Rio de Janeiro: Anvisa; 2003 [acesso em 2017 abr 4]. Disponível em: http://www.sbrafh.org.br/site/index/library/id/38. 
9. Agência Nacional de Vigilância Sanitária. Manual de tecnovigilância: abordagens de vigilância sanitária de produtos para saúde comercializados no Brasil. Rio de Janeiro: Anvisa; 2010 [acesso em 2017 abr 4]. Disponível em: http://search.bvsalud.org/ cvsp/resource/pt/lil-576426.

10. Moraes LO. Avaliação da qualidade de seringas agulhas comercializadas no Brasil [monografia]. Rio de Janeiro: Fundação Oswaldo Cruz; 2009. 90 p.

11. Moraes LO, Friedrich K, Melchior SC, et al. Eventos adversos e queixas técnicas relacionados ao fio para sutura cirúrgica comercializado no Brasil. Vigil Sanit Debate. 2013; 1(2):35-43.

12. Instituto Nacional de Metrologia, Qualidade e Tecnologia. Portaria Inmetro ${ }^{0} 503$, de 29 de dezembro de 2011. Aprova os requisitos de avaliação da conformidade para seringas hipodérmicas estéreis para uso único. Diário Oficial da União. 29 Dez 2011.

13. Brasil. Agência Nacional de Vigilância Sanitária. Resolução RDC nº 67, de 21 de dezembro de 2009. Dispõe sobre normas de tecnovigilância aplicáveis aos detentores de produtos para a saúde no Brasil. Diário Oficial da União. 22 Dez 2009.

14. Brasil. Agência Nacional de Vigilância Sanitária. Resolução RDC no 2, de 25 de janeiro de 2010. Dispõe sobre o gerenciamento de tecnologias em saúde em estabelecimentos de saúde. Diário Oficial da União. 26 Jan 2010.

15. Galmadez EVC, Carpinetti LCR. Aplicação das técnicas de planejamento e análise de experimentos no processo de injeção plástica. Gest Produção. 2004; 11(1):121-134.

16. Junior ELC. Gestão do processo produtivo. Curitiba: Ibpex; 2008.

17. Nickel EM, Ferreira MGG, Forcellini FA, et al. Modelo multicritério para referência na fase de Projeto Informacional do Processo de Desenvolvimento de Produtos. Gest Produção. 2011; 17(4):707-720.
18. Silva MF, Santos FP, Silva KF, et al. Exposição ocupacional a medicamentos antineoplásicos em clínicas veterinárias no município do Rio de Janeiro Vigil Sanit Debate. 2012; 1(1):34-42.

19. Kronhout H, Hoek F, Uitterhoeve $\mathrm{R}$, et al. Postulating a dermal pathway for exposure to anti-neoplastic drugs among hospital workers. Applying a conceptual model to the results of three workplace surveys. Ann Occup Hyg. 2000; 44(7):551-560.

20. Martins I, Rosa HVD. Considerações toxicológicas da exposição ocupacional aos fármacos antineoplásicos. Rev Bras Med Trab. 2004 Abr-Jun; 2(2):118-125.

21. Minoia C, Perbellini L, organizadores. Monitoraggio ambientale e biologico dell'esposizione professionale a xenobiotici: chemioterapici antiblastici. Milano: Morgan Edizioni Tecniche; 2000.

22. Rocha SD. Identificação dos riscos ocupacionais de equipes de saúde que atuam na administração e manipulação de quimioterápicos [dissertação]. Porto Alegre: Universidade Federal de Ciências da Saúde; 2014. $70 \mathrm{p}$.

23. Brasil. Agência Nacional de Vigilância Sanitária. Resolução RDC $n^{\circ}$ 16, de 28 de março de 2013. Dispões sobre Regulamento Técnico de Boas Práticas de Fabricação de Produtos Médicos e Produtos para Diagnóstico de Uso In Vitro e dá outras providências. Diário Oficial da União. 29 Mar 2013.

24. Vicente MG. Vigilância pós-comercialização de produtos para a saúde: A Tecnovigilância como uma prática de Saúde Pública. Bol Inform Tecnovigilância. 2012 Ago-Set; 3(3) [acesso em 2017 abr 4]. Disponível em: http://www.anvisa.gov.br/boletim_tecno/boletim tecno_julho_2012/PDF/bit3.pdf.

Recebido em 11/08/2017

Aprovado em 20/01/2018

Conflito de interesses: inexistente

Suporte financeiro: não houve 